do IST, cuja colaboração se agradece, procederam à correção das provas. No final destas sessões, os participantes reuniram-se no Centro de Congressos do IST para a divulgação dos resultados das provas e entrega dos prémios pelo Prof. Mário Nuno Santos.

Foi então encerrada a sessão, tendo sido servido um lanche a todos os participantes de forma a recuperar energias para a viagem de regresso.

Aos vencedores desta semifinal desejamos o maior sucesso para a final.

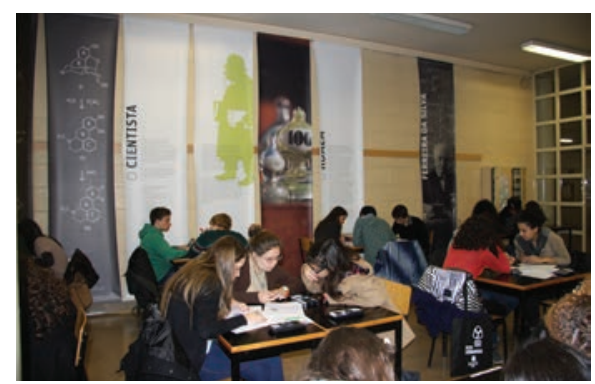

Prova teórica - Semifinal do Porto
Lista dos Vencedores da Semifinal DE LISBOA

\section{Medalhas de Ouro}

Escola Secundária de Aquilino Ribeiro - Porto Salvo

Prof. Responsável: Isabel Domingos Rebelo

Frederico Miguel Freire Neves

Diogo Miguel Nunes da Silva

Tiago Filipe Nunes da Silva

Medalhas de Prata

Escola Secundária Ferreira Dias Cacém
Prof. Responsável: Ana Paula Almeida

António José Santos Abreu

José Pedro Machado dos Santos

Miguel Cardoso Monteiro

\section{Medalhas de Bronze}

Escola Secundária Dr. Jorge Augusto Correia - Tavira

Prof. Responsável: Rosa Maria Leal Moreira da Palma

Carlos Moura Teixeira

Andreia Viegas

Laura Labrador

Jorge Morgado

Coordenador da Semifinal de Lisboa

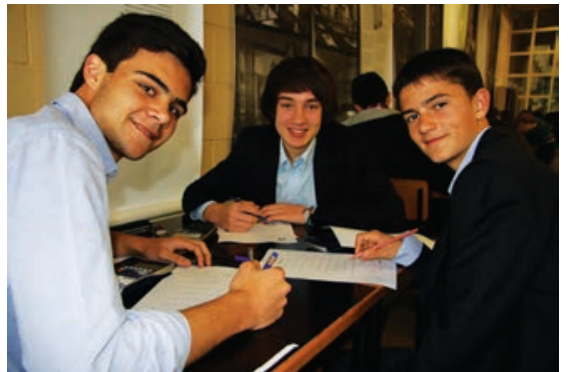

Equipa vencedora (Externato Cedros) na semifinal do Porto

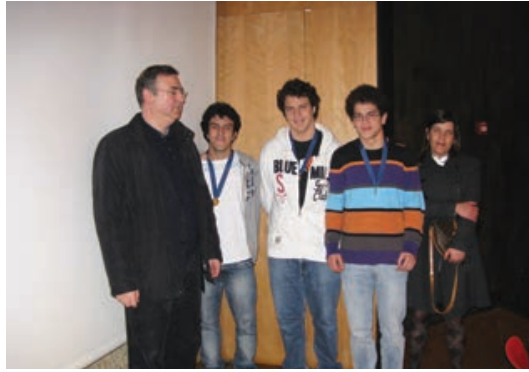

Fotografia da equipa vencedora da semifinal do IST - Lisboa (alunos e Profa) com o Presidente da SPQ, Prof. Mário Nuno Santos

\title{
Fase Regional de Bragança das Olimpíadas de Química 2012
}

Pelo sétimo ano consecutivo, a Fase Regional de Bragança das Olimpíadas de Química+ realizou-se na Escola Superior de Tecnologia e Gestão do Instituto Politécnico de Bragança (IPB), no dia 31 de janeiro. A organização do evento coube, uma vez mais, ao Departamento de Tecnologia Química e Biológica em colaboração com a Sociedade Portuguesa de Química (SPQ). Este ano, a prova laboratorial incidiu na determinação de sulfatos na água do rio Fervença recorrendo a um método espectrofotométrico.

Em 2012 as inscrições foram muitas, mas infelizmente o número de participantes esteve limitado à disponibilidade de recursos laboratoriais. Assim, as provas decorreram com um total de 84 alunos distribuídos por 28 equipas provenientes de 7 escolas do distrito, nomeadamente Colégio Torre Dona Chama, Escola ES/3 Abade de Baçal de Bragança, Escola EB2,3/S
D. Afonso III de Vinhais, Escola ES/3 Emídio Garcia de Bragança, Escola EB2,3/S de Macedo de Cavaleiros, Escola Secundária Miguel Torga de Bragança e Escola Secundária/3 de Mirandela. Após as provas, os alunos recuperaram forças com o almoço servido na cantina do IPB, seguindo-se a sessão de divulgação de resultados, onde todos os participantes receberam um certificado de participação. Uma vez mais, e mesmo em "tempos de crise económica", este evento contou com o já habitual e indispensável patrocínio do Crédito Agrícola, o que permitiu atribuir um prémio monetário às equipas com melhor desempenho. Os alunos das 3 equipas melhor classificadas viram o seu empenho recompensado com a atribuição do prémio "Crédito Agrícola", correspondendo à abertura de uma conta bancária no valor de $100 €$, $75 €$ e $50 €$, para cada um dos alunos das equipas que ficaram na 1. ${ }^{a}, 2 .^{a} \mathrm{e}$ 3. ${ }^{a}$ posições, respetivamente.
As equipas que arrebataram as três primeiras posições foram as seguintes:

Medalhas de Ouro

Escola Secundária/3 de Mirandela

Prof. acompanhante: Marília Vinhais

Ana Isabel Monteiro, Pedro Emanuel Valentim e David Pires Martins

Medalhas de Prata

Escola ES/3 Emídio Garcia

Prof. acompanhante: Luísa Maria Fernandes

Joana Piloto, Filipe Mota e Ana Margarida Gomes

\section{Medalhas de Bronze}

Escola ES/3 Abade de Baçal

Prof. acompanhantes: Florinda Cesária Fernandes e Cristiana Morais

Berta Gomes Gonçalves, Khanda Utnasunova e Maria Teresa Aguiar

As 3 escolas melhor classificadas foram premiadas com o financiamento 
da sua participação na Semifinal do Porto das Olimpíadas de Química+, financiamento este que inclui os gastos com a deslocação e alojamento das equipas. Novamente, tal só foi possível devido ao apoio monetário do Crédito Agrícola e ao apoio da Câmara Municipal de Bragança, que assegura o transporte das equipas à Semifinal que se realiza no Porto. Aos patrocinadores, um agradecimento pela aposta nas futuras gerações de químicos, e aos alunos, votos de sucesso e muito "entusiasmo químico"!

Joana Amaral (jamaral@ipb.pt) Coordenadora da Fase Regional de Bragança das Olimpíadas de Química ${ }^{+}$
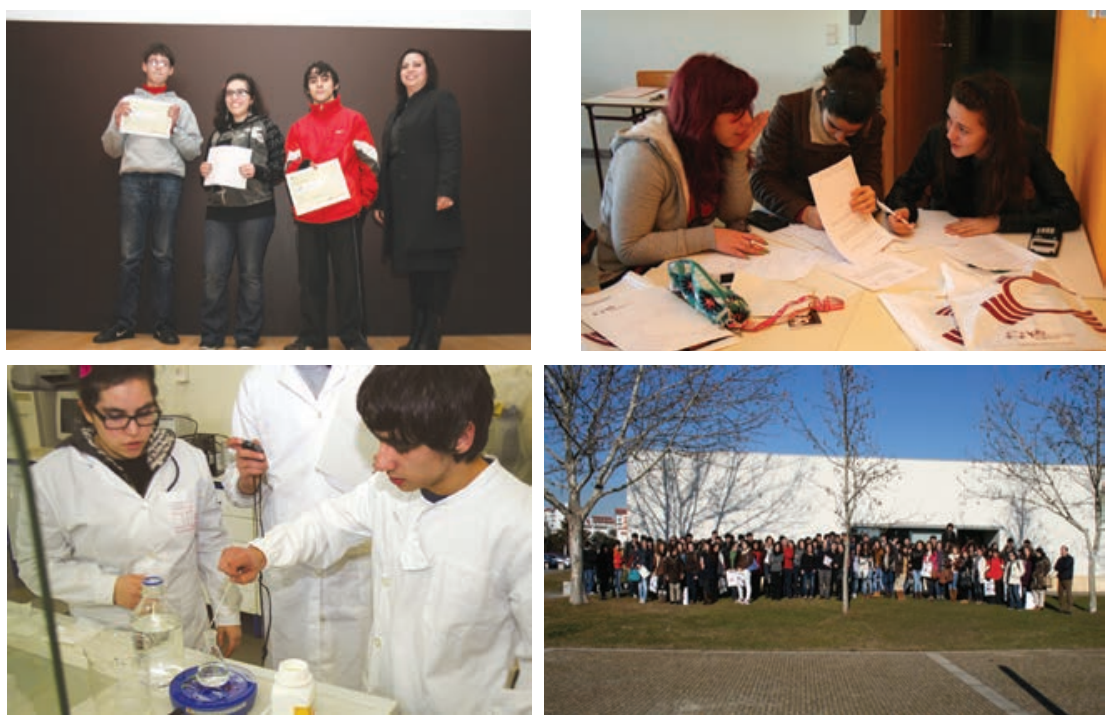

Fotografias do ambiente vivido nas provas. Em cima, à esquerda, equipa classificada em $1 .^{\circ}$ lugar

\section{Apurados os Finalistas da Edição de 2012 das Olimpíadas de Química JúnIOR (OQJ)}

No passado dia 14 de abril realizaram-se, por diversas cidades do país, as semifinais das Olimpíadas de Química Júnior. Em cada semifinal foram premiadas as 3 melhores equipas com as medalhas de "Ouro", "Prata" e "Bronze", respetivamente. Seguem-se as reportagens de diferentes provas em que se descreve a experiência vivida pelos participantes. Um agradecimento especial a todos os envolvidos na organização das provas e que contribuíram para a realização de mais esta "festa da química"!

Os alunos apurados disputaram a $\mathrm{Fi}$ nal Nacional que decorreu no dia 5 de maio de 2012.

Semifinal das Olimpiadas de Química JÚNIOR NA UNIVERSIDADE DO MINHO (BRAGA)

O Departamento de Química da Universidade do Minho organizou, pela oitava vez consecutiva, as Olimpíadas de Química Júnior em colaboração com a Sociedade Portuguesa de Química. No passado dia 14 de abril de 2012 estiveram presentes no Campus de Gualtar, em Braga, 90 alunos provenientes de 30 escolas da região, organizados em 30 equipas, acompanhados por mais de 30 professores.

Após uma curta cerimónia de boas vindas a todos os participantes, as provas tiveram início às $14 \mathrm{~h} 30 \mathrm{~min}$ e decorreram nos laboratórios de ensino do Departamento de Química e no Anfiteatro da Escola de Ciências. Durante cerca de duas horas, as 30 equipas responderam a 24 questões na prova de laboratório, baseadas em situações e montagens experimentais, e a outras 29 questões na prova de anfiteatro, baseadas em situações apresentadas com recurso a meios audiovisuais.

Pelas $17 \mathrm{~h} 00$ todos os participantes tiveram oportunidade de assistir a uma palestra intitulada "A Química é divertida e curiosa" apresentada pela Doutora Maria Manuela Silva. Foram sorteados alguns brindes pelos alunos participantes e professores acompanhantes (T-shirts com a Tabela Periódica, réguas, canetas da UM e livros de Química, estes oferecidos pela SPQ).

A divulgação dos resultados, momento alto das OQJ, aconteceu por volta das 17h30min. A medalha de ouro foi atribuída à equipa constituída pelos alunos Ângela Neto, João Rocha e Maria Carlos Pereira, da Escola EB 2,3 Júlio Brandão, de Famalicão. A medalha de prata foi entregue à equipa constituída pelos alunos Daniela Basto, Joaquim Santos e Sara Dourado, da Escola EB 2,3 de Cabeceiras de Basto. A medalha de bronze foi para a equipa constituída pelos alunos Gonçalo Terroso, José Ferreira e Nuno Silva, da Escola EB 2,3 de Cal-

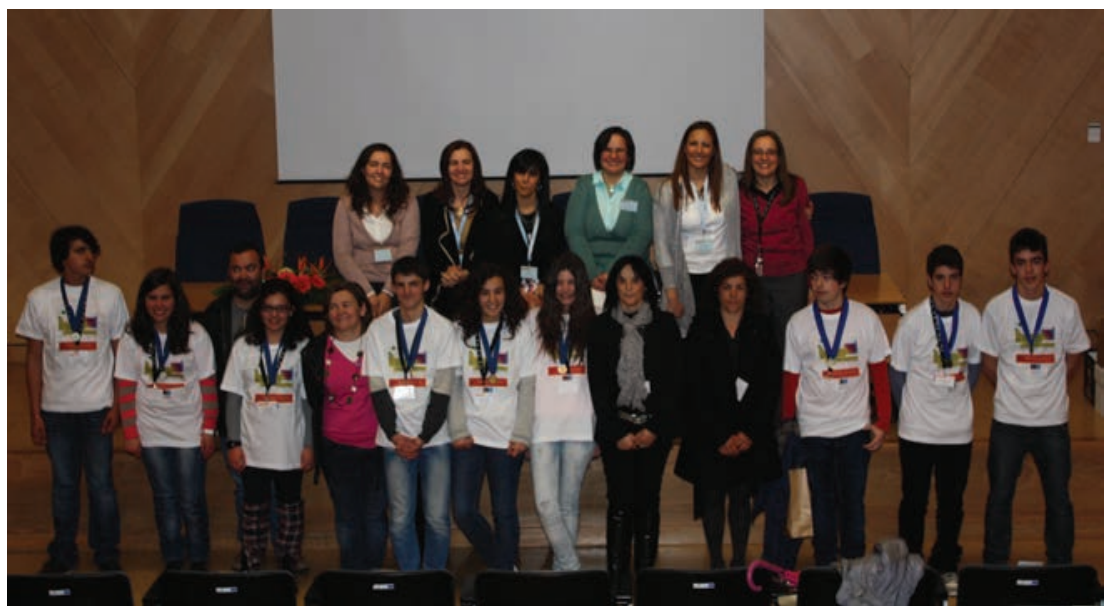

Comissão Organizadora e equipas vencedoras da semifinal das OQJ 2012 (U. Minho) 
das das Taipas, de Guimarães. Para além das medalhas da SPQ, estes alunos foram presenteados pelo Departamento de Química da UM com T-shirts com a Tabela Periódica, caixas de modelos moleculares e "USB Flash Drives", de valor variável consoante o lugar obtido.

Este evento contou com o patrocínio da SPQ, do Departamento de Química da Universidade do Minho, da Capital Europeia da Juventude e de algumas empresas. A cobertura das OQJ foi feita pelos órgãos de comunicação social da região.

Maria Manuela Silva, Maria José Medeiros, Maria Gabriela Botelho, Maria Manuela Raposo, Susana Costa e Sílvia Lima Organização das OQJ 2012 na U. Minho

Semifinal das Olimpíadas de Química JÚNIOR NA UNIVERSIDADE DE COIMBRA

Decorreram no dia 14 de abril, no Departamento de Química (DQ) da Faculdade de Ciências e Tecnologia da Universidade de Coimbra (UC), mais umas Olimpíadas de Química Júnior, as $8 .{ }^{\text {as }}$, numa organização conjunta da $S P Q$ e do $D Q$ da UC.

Este ano contou com a participação de 38 escolas, tendo estado em prova cerca de 170 alunos do ensino básico ( $8 .^{\circ}$ e $9 .^{\circ}$ anos), maioritariamente dos distritos de Viseu, Leiria e Coimbra, mas também de Aveiro, Guarda e Santarém. Foi um dia em que estes alunos puderam, para além de efetuar diversas provas de química (8 atividades laboratoriais divididas em 3 laboratórios e uma componente teórica), conhecer a UC através da visita à exposição 'Da cartografia do poder aos itinerários do saber' (comemorativa do centenário da Faculdade de Ciências da UC), patente na Galeria

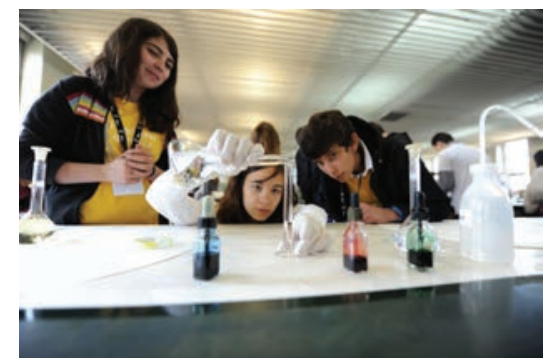

de Zoologia do Museu da Ciência, e de uma apresentação de um docente do DQ, o Dr. Paulo Abreu, que proferiu uma palestra ('A química do outro lado do espelho') sobre como a simetria está presente em todo o lado, nomeadamente na química do nosso dia-a-dia.

Em cada ano que passa vamos notando que os nossos olímpicos vêm cada vez mais bem preparados e assim a grande maioria das equipas teve resultados médios de $80 \%$, sendo que a equipa vencedora ultrapassou os $90 \%$. No fundo foram todos vencedores, mas para registo aqui ficam os três primeiros classificados. Em primeiro lugar ficou a equipa "Colecionadores de isótopos", constituída pelos alunos Pedro António P. Azeitona, Francisco G. Contente e João André A.F.V. Gomes, orientada pelo professor Desidério Carreira Pires, da Escola Básica 2,3 Frei Estêvão Martins, de Alcobaça. Um professor que já conseguiu quatro vitórias em anteriores edições!

O segundo lugar pertenceu à equipa "stephens_alfa", constituída pelos alunos Ana Aparício, Carolina Lopes e Tiago Silva, orientada pela professora Sandra Figueiredo, da Escola Básica dos $2 .^{\circ}$ e $3 .^{\circ}$ Ciclos de Guilherme Stephen, da Marinha Grande.

Finalmente, o terceiro lugar foi conquistado pela equipa "stephens_beta", constituída pelos alunos João Francisco, Manuel Simões e Mariana Vaz, orientados pela mesma professora e escola dos classificados em segundo lugar. A professora Sandra Figueiredo foi aliás a professora acompanhante dos primeiros vencedores das Olimpíadas de Química Júnior de Coimbra no já distante ano de 2005 , na altura com uma equipa da escola de São Martinho do Porto. E com que confiança vinham estes concorrentes!...

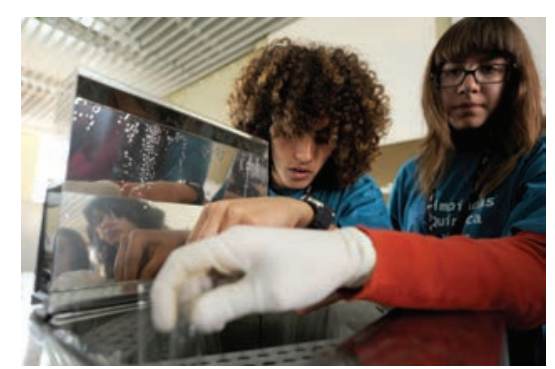

Fotografias do ambiente vivenciado na semifinal de Coimbra
Em ambos os casos os professores acompanhantes ilustram o quanto é relevante e importante o papel de professor na formação dos nossos jovens e neste caso no gosto e formação em química.

No momento em que se escrevem estas linhas apenas posso desejar às duas primeiras equipas a melhor sorte na final nacional, que decorrerá no próximo dia 5 de maio em Lisboa no IST.

A organização das OQJ 2012 em Coimbra congratula-se com todos os participantes e agradece o patrocínio da Caixa Geral de Depósitos, da SPQ e da FCTUC, bem como o apoio da Porto Editora.

J. Sérgio Seixas de Melo

Organização das OQJ 2012

na U. Coimbra

Semifinal das Olimpíadas de Química JÚNIOR NA UNIVERSIDADE DA BEIRA INTERIOR (COVILHÃ)

Pelo oitavo ano consecutivo decorreu, no Departamento de Química da Universidade da Beira Interior (UBI), a semifinal regional das OQJ. Nesta edição participaram 87 alunos, integrados em 29 equipas, provenientes de 15 escolas dos distritos de Castelo Branco, Guarda, Portalegre e Viseu.

O evento contou, na sua sessão de abertura, com a presença da Presidente do Departamento de Química, do representante da UBIQuímica-Núcleo de Estudantes do Departamento de Química e da comissão organizadora, que deram as boas-vindas a todos os participantes.

Durante a manhã, as equipas participantes realizaram duas provas com questões de escolha múltipla, uma de carácter mais teórico, que teve lugar no anfiteatro Prof. Pinto Peixoto, e outra de carácter experimental, que decorreu nos laboratórios de Química. Durante este período, os professores acompanhantes puderam participar numa visita ao Núcleo da Real Fábrica Veiga/Centro de Interpretação dos Lanifícios, do Museu de Lanifícios da Universidade da Beira Interior. Seguiu-se o almoço dos participantes na Cantina de Sto. António da UBI. 
A cerimónia de encerramento teve início às $15 \mathrm{~h} 30 \mathrm{~min}$, com a divulgação dos resultados e a entrega dos prémios, a qual foi efetuada pela Presidente da Faculdade de Ciências da UBI e pelo representante do Banco Santander Totta. A medalha de ouro foi atribuída à equipa "Os Quarks", constituída pelos alunos Beatriz L.G. Coelho, Madalena João C. Antunes e Ricardo R. Manso, acompanhados pela professora Maria Florinda R.B. Carrega, da Escola EB 2,3 Cidade de Castelo Branco. A medalha de prata foi atribuída à equipa "Eureka!", constituída pelos alunos Ana Carolina P. Abreu, João Pedro M. Dias e Rodrigo B. Cruz, acompanhados pela professora Cristina Isabel P.P.C. Albino, da Escola Evaristo Nogueira de S. Romão. A medalha de bronze foi atribuída à equipa "Os AlbiQuímicos", constituída pelos alunos Bruno M. Ribeiro, Mariana C.R.S. David e Renato M.F. Matos, acompanhados pela professora Rosa Maria Ribeiro, da Escola EB 2,3 Cidade de Castelo Branco. Finalmente, foi atribuída uma Menção Honrosa à equipa classificada em $4^{\circ}$ lugar, constituída pelos alunos Gonçalo T.S. Marques, Joana M.L. Cabaço e Mariana Q.E. Pereira, acompanhados pelas professoras Alexandrina Feliciano e Isilda Lourenço, da Escola Básica Integrada João Roiz de Castelo Branco. A semifinal da Olimpíadas da Química Júnior na UBI foi encerrada em clima de festa com a atuação da sempre animada e bem-humorada Tuna Académica "Já b'UBI \& Tokuskopus", à qual se seguiu um lanche convívio.

A organização agradece à Reitoria da UBI e ao Banco Santander Totta pelo patrocínio e apoio a esta iniciativa, bem como à Rotoquímica e à Casa da Lagariça. Aos docentes do Departamento de Química, funcionários e, em especial, aos alunos do Departamento de Química dos $1 .^{\circ}$ e $2 .^{\circ}$ ciclos de es-
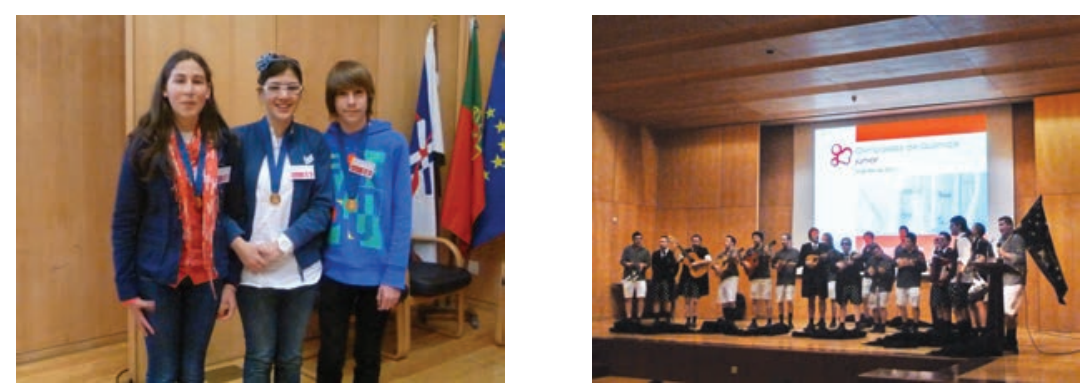

Equipa classificada em $1 .^{\circ}$ lugar e atuação da tuna nas OQJ na UBI

tudos em Química Industrial, Química Medicinal, Bioquímica e Biotecnologia, cuja colaboração foi essencial para levar a bom termo esta iniciativa, o nosso sincero agradecimento. A todos os participantes destas Olimpíadas, o nosso bem-haja pela vossa presença e entusiasmo.

\section{Maria de Lurdes Franco Ciríaco e Maria José Alvelos Pacheco Organização das OQJ 2012 na UBI}

Semifinal das Olimpíadas de Química JÚNIOR NA UNIVERSIDADE DO ALGARVE (FARO)

No dia 14 de abril decorreu, no Departamento de Química e Farmácia da Universidade do Algarve, mais uma edição das OQJ, este ano com 23 equipas inscritas, tendo havido oito desistências, das quais sete causadas pela falta do transporte que tinha sido inicialmente prometido pela Câmara Municipal de Albufeira, não tendo por isso este concelho tido a representação inicialmente prevista.

Participaram escolas dos concelhos de Olhão, Odemira, Loulé e Faro, podemos assim contar com 15 equipas envolvendo um total de 45 alunas e alunos dos oitavo e nono ano do ensino básico.

As provas tiveram uma componente prática, divida por quatro laboratórios, num total de 16 experiencias distintas envolvendo, quer a observação de fenómenos químicos, quer a realização das mesmas por parte dos concorrentes, e uma componente teórica, onde os concorrentes puseram à prova a sua capacidade de resolução de problemas e os seus conhecimentos de química.

A competição foi renhida tendo-se verificado a seguinte classificação:

1. ${ }^{\circ}$ Lugar

Equipa: Alexandre Carvalho, Paulo Cabrita e Raquel Jacob

Escola Básica dos $2 .^{\circ}$ e $3 .^{\circ}$ Ciclos José Carlos da Maia - Olhão 2. ${ }^{\circ}$ Lugar

Equipa: Adriana Catarino, Anna Bogatyreva e Carolina Estevão

Escola Básica dos $2 .^{\circ}$ e $3 .^{\circ}$ Ciclos Eng $^{\circ}$ Manuel R. Amaro da Costa de Sto. Teotónio - Odemira 3. ${ }^{\circ}$ Lugar

Equipa: Beatriz Ferrinho, Catarina Barão e Ana Carolina Mendinhos Escola Básica dos $2 .^{\circ}$ e $3 .{ }^{\circ}$ Ciclos de D. Afonso III - Faro

A organização contou com a colaboração dos técnicos do Departamento de Química e Farmácia, bem como de diversos docentes do mesmo departamento, e de alunos do Núcleo de Ciências Farmacêuticas e da Licenciatura em Bioquímica.

\section{José Moreira, Catarina Pires}

e Rosário Lopes

Organização das OQJ 2012 na U. Algarve
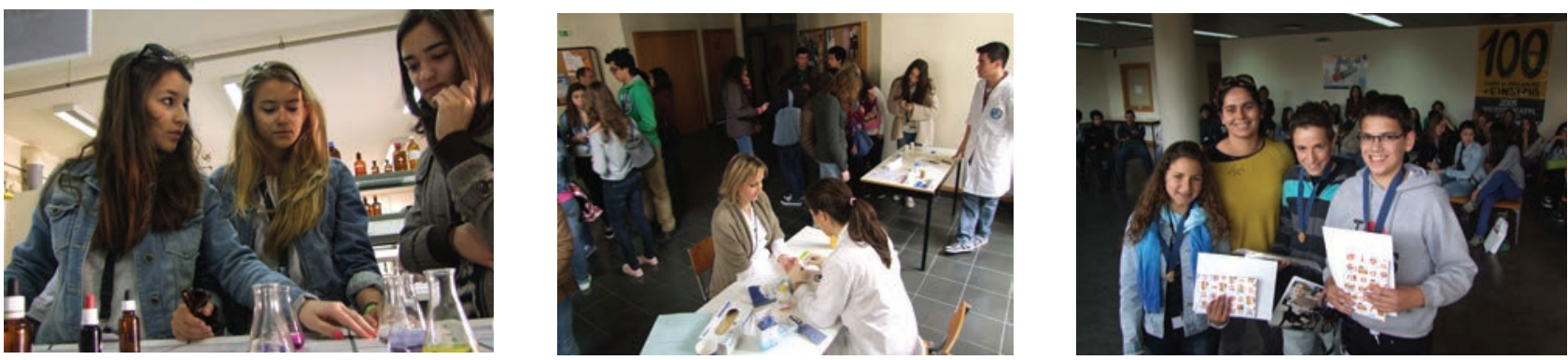

Fotografias do ambiente vivenciado na semifinal de Faro e vencedores da prova (à direita) 
Semifinal das Olimpíadas de Química JÚNIOR NA FACULDADE DE CIÊNCIAS DA UNIVERSIDADE DE LISBOA

Os participantes da semifinal das OQJ que decorreu no Departamento de Química e Bioquímica (DQB) da Faculdade de Ciências da Universidade de Lisboa (FCUL) começaram a chegar ao campus da FCUL bem cedo e, de acordo com o programa, a partir das $9 \mathrm{~h} 00$ foram recebidos com um pequeno-almoço, gentilmente oferecido pela Presidência do DQB.

Pelas 10 h00 teve lugar, num dos anfiteatros do edifício C8, a Abertura Oficial das OQJ, onde, após discursos alusivos ao evento dando as boas vindas aos participantes, foram enunciadas as regras. Seguiu-se um período de $2 \mathrm{~h}$ e 30 min destinado à realização das provas, em que os participantes foram chamados a responder a um conjunto de 30 questões, algumas de carácter teórico, respondidas numa sala de aula, e outras de carácter mais experimental (observações experimentais, medições, etc.), montadas em triplicado em 3 laboratórios de química. Cada uma das 33 equipas foi monitorizada por um delegado da FCUL, recrutado entre alunos e docentes, responsáveis por acompanhar a prestação das equipas, pela deslocação destas entre as salas e os laboratórios, cronometrando os tempos de realização.

Seguiu-se o período do almoço. Enquanto eram corrigidas as provas, por um júri de 5 docentes do DQB, decorreu, num laboratório, um interessante conjunto de experiências preparado por alguns docentes do DQB, que, visivelmente, animou os participantes grande parte do período da tarde.

Eram 16h30min quando teve lugar a Sessão de Encerramento das Olimpí- adas. A todos os participantes foram distribuídos prémios e diplomas de participação.

$\mathrm{Na}$ prova participaram alunos e professores de 17 escolas participantes: Colégio Pedro Arrupe, Escola Básica Integrada 1,2,3/JI Vasco da Gama, Escola Secundária 2,3 D. João V, Escola Secundária Dr. António Carvalho Figueiredo, Escola Secundária Miguel Torga, Escola Básica 2,3 Fazendas de Almeirim, Escola Básica 2,3 Roque Gameiro, Colégio Integrado Monte Maior, Escola Básica 2,3 S. Julião da Barra, Escola Secundária Alves Redol, Escola Secundária Ferreira Dias, Agrupamento de Escolas Damião de Goes, Escola Básica 2,3 dos Pombais, Colégio de São Tomás, Escola Básica Jl de Ribamar, Escola Básica 2,3 dos Castanheiros e Colégio Vasco da Gama.

Após ter sido anunciada a posição de cada equipa, foram chamados ao palco todos os elementos das 3 equipas classificadas nos primeiros lugares e anunciados os $3 .^{\circ}, 2^{\circ}$ e $1 .^{\circ}$ classificados, a quem foram distribuídos os prémios e entregues as medalhas de bronze, prata e ouro, oferta da SPQ, acompanhadas de diplomas, para alunos e respetivas escolas.

\section{1. ${ }^{\circ}$ Lugar}

Equipa: Jéssica C. Soares, Pedro A.S. Reis e Raquel R. Gama

Escola EB 2,3 Roque Gameiro 2. ${ }^{\circ}$ Lugar

Equipa: Beatriz P. Barata, João P.S. Correia e Raquel A. Ribeiro

Colégio Vasco da Gama

3. ${ }^{\circ}$ Lugar

Equipa: Ana Sofia G.S. Vicente, Catarina A.S. Cardeta e João M.G. Nunes

Escola EB 2,3 de Fazendas de Almeirim

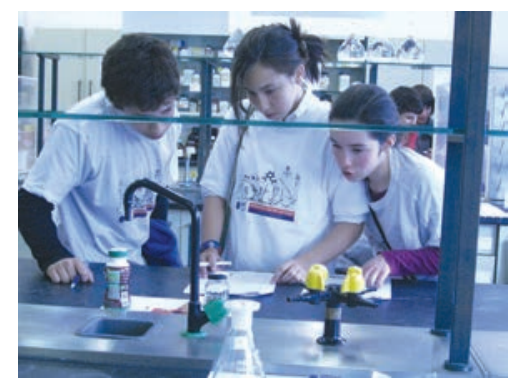

Mais um êxito desta iniciativa, pois foi geral o entusiasmo e o agrado com que participaram professores e alunos das escolas, muito se devendo ao empenho e colaboração de alguns docentes e alunos do DQB.

Agradecemos o patrocínio das seguintes entidades: Livraria Escolar Editora, Banco Espirito Santo (BES), Faculdade de Ciências da UL e Departamento de Química e Bioquímica.

Maria Manuela G.S. Rocha e Carlos Manuel F.S. Borges

Organização das OQJ 2012 na FCUL

Semifinal das Olimpiadas de Química JÚNIOR NO INSTITUTO SUPERIOR TÉCNICO (LISBOA)

A semifinal das Olimpíadas de Química Júnior no Instituto Superior Técnico (IST) iniciou-se com a receção aos alunos e professores acompanhantes pelas $10 \mathrm{~h} 00$ na Torre de Química do IST. Estavam inscritas 24 escolas, tendo comparecido 19 , num total de 27 equipas. De realçar a presença de uma equipa da Madeira (Escola Básica 2,3 Caniço), apesar do contexto económico atual.

As provas tiveram início pelas 10h30min, tendo as equipas sido agrupadas em "Famílias de elementos da Tabela Periódica". As provas envolveram observações, pequenas experiências e respostas a questionários e adivinhas em torno da Química, que ocuparam os alunos até cerca das $12 \mathrm{~h} 00$. Os alunos foram guiados nesse percurso por professores do Departamento de Engenharia Química (DEQ) do IST e alunos do Núcleo de Engenharia Química (NEQIST) e acompanhados, nos laboratórios, por alunos do NEQIST.

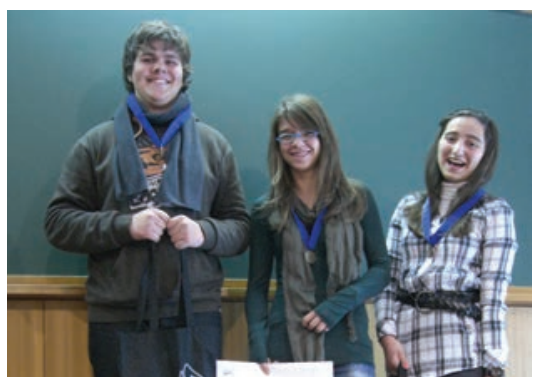

Fotografias do ambiente vivenciado na semifinal no DQB-FCUL e vencedores da prova (à direita) 